\title{
Supporting personal world-views in an envisioning system.
}

\author{
Ian D. Bishop+, R. Bruce Hull IV* and Christian Stock \\ Department of Geomatics \\ The University of Melbourne, Australia \\ idbishop@unimelb.edu.au
}

\begin{abstract}
+ corresponding author
* This paper was prepared while Bruce Hull was a Visiting Fellow in Melbourne. His usual address is the Department of Forestry, Virginia Polytechnic Institute and State University, USA (rbhull@vt.edu).
\end{abstract}

\begin{abstract}
This paper describes an Envisioning System (EvS) designed to help rural communities contemplate landscape level changes. Simulations and models project current conditions into the future according to the constraints of scenario-based planning and available land use choices. Possible futures are represented through visual (2D, 3D and iconic) indicators. This paper defines four distinct world views (romantic, pastoral, ecological, and economic) and then reviews system design in the light of these views. Two key systems aspects discussed are the indicators of environmental conditions, and the styles of data presentation. A developed EvS was tested in two public workshops. In one the world views were explicitly introduced, in the second they emerged naturally through exploration of futures. Our findings suggest that awareness and understanding of four major world-views can help plan and evaluate major software systems while also providing a convenient structure for analysis of results.
\end{abstract}

Keywords: Envisioning systems, world-views, virtual reality, community values

\section{Software}

Name of software: PA-server, PA-render, PA-GIS, PA-PDA

Developer and contact address: Department of Geomatics, University of Melbourne 3010, Australia Telephone, fax and email numbers: +61 38344 6771, +61 39347 2916, cstock@unimelb.edu.au Year first available: 2003, ongoing development 
Hardware required: Pentium $1 \mathrm{GHz}$, 3D capable graphics card (e.g. Nvidia Geforce), Pocket PC with Bluetooth, Bluetooth Access Point, Network Hub

Software required: Microsoft Windows 2000, Microsoft Pocket PC 2002, OpenGL Performer 3.0, ArcGIS

Desktop 8

Program language: $\mathrm{C}++$

Program size: $2.5 \mathrm{MB}$

Availability and cost: these software are not available in their present form except for collaborative research purposes.

\section{Introduction}

Communities want to control their destinies. They struggle, however, dealing with complex, incomplete, compartmentalized and contradictory information about their communities and about possible futures. Yankelovich (1991) describes this phenomenon as a crisis in governance and suggests that a clear vision of possible goals and outcomes provides one of the most effective means to engage in the social learning and meaningful action communities need to realize their goal of controlling their destinies. Software products such as What if? (Klosterman, 2001) and CommunityViz (Kwartler \& Bernard, 2001) assist communities exploring and envisioning possible future conditions and the consequences of planning decisions. This paper describes an Envisioning System (EvS) designed to help rural communities contemplate landscape level changes. Simulations and models project current conditions into the future according to the constraints of scenario-based planning and available land use choices. Possible future conditions are represented visually through maps, visual simulations and indicator icons. The goal of an EvS is to help community members negotiate desired future conditions and implement policies which shape land use changes that produce these desired conditions.

An EvS differs from a Decision Support System (DSS) following the reasoning of Brail and Klosterman (2001). The goals of EvS are longer range than typical for DSS and less analytical. EvS is less directed towards identifying best solutions and more directed towards identifying achievable directions. EvS attempts to facilitate collaboration rather than enable executive decisions.

There exist important and considerable challenges to collecting, modeling, maintaining, and displaying the enormous amounts of data required of an EvS. This paper focuses on the qualities of system architecture that are critical to engaging stakeholders. For an EvS to be effective it must engage stakeholders in the envisioning process about their community. If stakeholders are alienated or excluded, then the vision will be partial and efforts to implement that vision may be resisted.

People interpret information through their world-views (Gundersen, 1995; Michael 1995). If we wish to engage people and provide them with the means to understand the consequences of their behaviors, so as to create desired futures, then we face three distinct tasks: 1) allow their worldviews to be represented, 2) help them see the world through eyes of other stakeholders, and 3) facilitate negotiations about possible futures. To accomplish these tasks, people must have some control over the language (including modes of presentation and communication) and indictors used to represent the environment and future scenarios. Information systems that merely transfer or represent someone else's (e.g., an analyst's) worldview, or present information in a format 
which is not suitable for the particular user, are insufficient to motivate community engagement and promote change.

We identify two major factors of EvS architecture that may affect stakeholder participation: the indicators of environmental conditions, and the data presentation styles. The purpose of this paper is threefold: 1) to describe these factors and why they may affect stakeholder participation; 2) to propose a world-view framework for anticipating the different stakeholder preferences and thus enabling some system development to proceed prior to stakeholder involvement; and 3) to illustrate these issues through a case study of a developed EvS (Stock \& Bishop, 2001) as used in community workshops.

\section{System Design Factors}

\section{Indicators}

Indicators are the heart-and-soul of an EvS. They represent the environmental conditions that are modeled, simulated, or otherwise projected into the future. They are the topic of stakeholder discussions. They define and constrain the decision space because futures characterized by conditions other than these indicators cannot be projected, considered, and negotiated. What indicators of environmental quality should an Envisioning System forecast? This question presents perhaps the most important and difficult challenge of systems development. The question must be answered in the context of two competing demands. For various reasons outlined below, the system needs to be flexible and incorporate many indicators. In contrast, for obvious reasons of limited analytic and computational resources, only a finite set of indicators can be inventoried, modeled, and incorporated into any computer system that is developed at reasonable cost and intended for wide use. Choosing the right indicators can make the difference between relevance and irrelevance, success and failure.

Lessons from collaborative planning suggest that flexibility can make the difference between successful planning efforts and those that gather dust on shelves or become stalled in courts. Active and engaged public participation is a fundamental prerequisite for "sustainable development," "ecosystem management," "adaptive management" and related Agenda 21 planning initiatives (United Nations, 1992). Information systems that constrain the decision space with limited indicators will exclude or misrepresent stakeholders causing them to be frustrated and/or drop out of the process. Successful planning efforts must minimize stakeholder attrition, particularly attrition attributable to poor systems design. Success requires broad stakeholder involvement and investment in the outcome (Walker et al., 2002).

An additional motivation for flexible indicator selection comes from the critique of environmental science. What counts as environmental quality? What should be the goals of conservation? There are no simple answers to these essential conservation questions. There are no "natural imperatives" or "scientific laws" that answer these questions. Recent ecological theory tells us that nature is both chaotically complex and continuously changing. The landscape is dynamic at all scales of space and time and thus many conditions of nature have and will continue to exist. Ecological science cannot identify one of these many possible natures as being better than another without invoking some value system that answers the question "better for 
what purpose?" Neither nature, nor science (as the study of nature), can claim to know what is "best" for nature (Botkin 1990; Pickett et al. 1997; Worster 1994). Many indicators of environmental quality exist: soil erosion, soil salinity, water quality, ecosystem health, biodiversity, are just a few. Each indicator represents a partial characterization of the infinitely possible conditions that define environmental quality. Care must be taken in selecting indicators relevant to the stakeholders, not just those that are scientifically precise and analytically predictable (Bergquist and Bergquist, 1999; Robertson and Hull 2001b).

\section{Presentation}

Erwin (1992) identified diagrams, maps, graphs and pictures as typical presentation forms for spatial data. Diagrams are abstract and schematic, and are used to explore structural relationships between parts. Maps involve scaled representations using a consistent system of reference (e.g. coordinate system), and allow inferences about dimensional and spatial relationships. Graphs are concerned with representation of statistical and quantitative data. Pictures are primarily concerned with impression, expression and realism.

This classification of presentation types reveals certain dimensions: level of abstraction, presence of coordinate system, quantitative data, impression and realism. Within each classification dimension there may be anything from a binary distinction (static versus dynamic) to a full spectrum of options (range of colors and textures). The first job therefore is to establish exactly what the dimensions are which define our information presentation options.

As Table 1 suggests, there are many forms of presentation for each possible combination... Some authors have sought to give specific names to particular display modes within the classification spectra. Verbree et al (1999) for example, distinguished the representation of urban spatial data as "plan view", "model view" and "world view".

Presentation can also be interactive, in which case the interaction options for the EvS must be designed with the user in mind. The system can be controlled by a single designated (and expert?) operator or interacted with by all stakeholders. Navigation, selection, model specification etc can be designed in different ways and through different interfaces (e.g. the 2D or the 3D view). Stoakley et al (1995), for example, have reviewed navigation systems and identified options include gaze directed movement, pointing, and map-based relocation.

To a considerable extent the mode of presentation is constrained by the choice of indicators. Thus, for example, the creation of local jobs does not require a map or a picture. Scenery, on the other hand, is most easily interpreted through a realistic picture.

Presentation is also a function of the display mode. Options include posters (necessarily static), computer screen, projection (front or rear) and head-mounted displays. We do not review these options here except to reflect that our three-screen rear-projected system (Figure 1) worked well in our workshop context (Section 4 and 5).

\section{World-Views}

Envisioning systems must enable stakeholders to evaluate the consequences of potential actions and envision possible futures. Such functionality cannot be implemented in real-time, during the 
negotiations, but must be built into the system. Data collection, model testing, and interface building are required. A method for identifying most appropriate presentation and interface modes and outcome indicators prior to stakeholder involvement is needed. One possible solution is to anticipate probable world-views and develop the system accordingly. The world-views need not be exhaustive or exclusive to be helpful. Individual stakeholders need not be pigeonholed into a single world-view but instead might find meaningful indicators and presentation styles in several world-views. The world-views simply provide a starting place for system design or evaluation.

At least four different world-views about environmental change appear repeatedly in the history of the Western world (Dunlap 1999; Robertson and Hull 2001a): economic, romantic, pastoral, and ecological. Each of these is described below.

Economic: From a capitalist world-view, nature is a resource waiting for use and development. To leave nature alone is considered wasteful, just as leaving idle a built factory would be considered wasteful. Agricultural productivity, industrial development, and tourism provide familiar frameworks for identifying resources, but so can ecosystem services (i.e., water purification, nutrient recycling, and carbon sequestration).

Romantic: Romanticism is a view of the world based on several well-rooted strands of aesthetic and spiritual thought. The movement emerged principally in European literature but spread throughout the Western world as a response, both negative and challenging, to the increasingly godless, inorganic, and urbanized world produced by ever expanding developments of modern science, technology, and industry. Romantics look to nature as a moral compass as well as aesthetic entertainment. Nature is assumed to know best and is soiled by human intervention. Nature provides profound spiritual enlightenment and reveals deep moral truths. Nature is a place for recreation and contemplation, not active manipulation and exploitation.

Pastoral: Nature provides a lifestyle that nurtures a rural culture, teaches virtue, and instills independence and moral excellence. Human labor combines with nature to create a pastoral landscape and agrarian lifestyle. Technology complements rather than replaces human labor; nature is managed rather than replaced by biotechnology. Small family farms are dispersed over a landscape and connected by small towns servicing the rural economy. High value is placed on social and community interactions, connections to place, and simple (sustainable) lifestyles.

Ecological: Nature is viewed as a collection of ecological processes and content such as integrity, resilience, and biodiversity, often to the exclusion of cultural history (e.g., Worster 1994; Takacs 1996). When a specific place is considered in its spatial and temporal context, its current characteristics (and its residents) become lost in the bigger picture. Native species, presettlement conditions, endangered species, keystone predators, and wildlife habitat surpass concerns about economic returns or recreational benefits. 


\section{Case Study}

Setting

In Stock and Bishop (2002) we introduced an EvS developed for the Cudgewa Valley in northeastern Victoria, Australia. The focus area is 16 by $16 \mathrm{~km}$. It is primarily farming land in the valley bottom and lower slopes with forest on the ridges. There is a large private pine plantation and some farmers are developing both hard (Eucalypt) and soft (Pinus) wood plantations. In the north-west is Burrawa-Pine Mountain National Park, but it is infrequently visited. In Cudgewa town (population about 100) there is one bed-and-breakfast establishment. The town of Corryong (12 km away) is the regional centre.

This is a valley whose wider significance is in its role in water collection for the much larger Murray-Darling system and its proximity to Australia's major snow-fields. However, the residents, who are primarily farmers, are under pressure because of long-term falling stock prices. The aging population is not being replaced, as the children move out of the area, and land management levels are low on some properties resulting in the spread of weeds and poor management of water courses. Structural change is required for survival of the valley as a healthy rural community. This change is beginning to occur and the EvS is intended to help the community understand and manage the change that many of the residents agree is inevitable.

\section{System Design}

Our EvS has three major parts: a geographic information system (GIS), a three-dimensional visualization system, and community interaction and commentary system based on handheld computer devices (sometimes called personal Digital Assistants - PDA). All are network linked with software designed to trigger changes in the visualization sub-system on the basis of GIS activity or community responses. Visualization uses a portable virtual reality (VR) setup that provides interactive exploration of possible landscape changes by rendering the environment real-time onto three screens using three rear-projectors to give a 135 degree field-of-view. Figure 1 shows the hardware configuration. The three projectors are fed from a single computer (running Windows OS) through a graphics card with three output channels. The software includes a server program that manages the communication between the several software components and a display program based on OpenGL Performer.

A virtual 3D model of the valley (Chen et al. 2002) includes a terrain model and 3D objects representing features such as buildings, trees, fences, and roads. 3D models representing features typical for each type of land cover (e.g. trees for forests) were used to visualise different land cover options. Individual farms are divided, based on farmer advice, into distinct management units.

The GIS provides a 2D view of the region and serves as an interface for stakeholders to interact with the system. Stakeholders select from possible land uses for each management unit to create possible future land use scenarios for the entire valley. Scenarios for the valley can also be created in advance, based for example on scientific or economic analysis, then presented and explored in the VR system. 
Impacts of the selection will be seen immediately in the VR view. Additionally, the GIS component calculates the non-visual impacts impacts of proposed land use changes to the various indicators discussed below. The outcomes of these computations are presented on the visualization screen as a set of icons which are colour coded to illustrate the direction and degree of change. Since the non-visual impacts have to be computed in real time, we use simplified (executive summary) models to predict general trends (e.g. increase/decrease in water quality for the whole valley).

The system was used in a workshop environment. Stakeholders invited to the workshops were able to create, view, alter, discuss, and evaluate possible scenarios through the GIS operator or using the handheld computers. For example, assessments of alternative scenarios provided by stakeholders were displayed on the VR view to serve as the basis of further discussion.

\section{Indicators}

The initial design of the EvS was based of our own judgments, discussions with the farming community and input from the local water catchment management authority. This was done without reference to the concept of multiple world-views. The widely recognized categorization of world-views (above) provides the opportunity to reevaluate our system design and thus consider changes that might improve its utility as a community tool. Based on discussions with stakeholders, issues raised in government reports and articles in local newspapers, we originally identified seven icon-based indicators: water quality, water quantity, erosion, weeds, salinity, native animal habitat and employment (identified in bold in Table 2). These proved useful in the workshops and were found to have an effective on stakeholder assessments. As is evident from the table, these indicators are fairly well spread among the world-views except that the romantic views appears neglected. However, romanticism was implicit in the system design and is captured by realistic visualization as a central design tenent. The local landscape ('scenery' in Table 2), therefore, is available for community evaluation. Examining our initial design through the lens of world-views suggests that a large number of potential indicators are not in our initial systems design. However, the only indicator mentioned in the workshop as a key absentee was economic outcome.

Given the perspective of four worldviews we conclude that the proposed EvS may have inhibited participation by significant stakeholders. Stakeholders that visit but do not live in the area might be concerned with recreational use and other qualities indicated by the Romantic world-view. Stakeholders living in nearby communities might be more interested in economic indicators, especially those related to their dependence on agriculture, forestry, and tourism economies. Stakeholders that neither visit nor live in the area, but reside in distant large urban areas and influence land uses through voting and lobbying for environmental issues may prefer more ecological indicators such as biodiversity.

\section{Presentation}

Ecological indicators such as spread of weeds and exotic/native species could be presented using a more abstract 3D view which doesn't display the landscape as realistic, but rather displays abstract symbols that show the dispersion of the indicator over the landscape. We did not use this 
approach - preferring to minimize ambiguity by using textured 3D Objects - but this aspect of the presentation was criticized for not having a realistic density of blackberry bushes (one of the worst of the weeds) in our simulations.

Economic indicators might best be aggregated into tables. Also, instead of using a texture based on aerial photographs draped over the DTM, we could use GIS maps to display non-visual information such as wildlife migration corridors, water flows, remoteness, etc. This would also have the advantage of showing how non-visual impacts could change over space and time if the $3 \mathrm{D}$ view is animated. Figure 2 briefly summarises and illustrates these conjectures.

We have only limited notions of how a preferred interface may correlate with world-view, but it seems likely that preferred user interface options depend more on training and familiarity than on world-view. This suggests the retention of maximum flexibility in systems design. However, such flexibility also complicates the development process and also may confuse untrained (i.e. community workshop based) users. During our workshops we had three different user levels offered through the three computer interfaces: PDA, GIS and VR system. Different functions were available through each interface. Navigation was from the individual PDAs held by the general public (one PDA to each 3 or 4 people), through the GIS as operated by a trained local resident or via expert control on the main rendering (VR) computer. The level of power and complexity of the interface increased according to user expertise.

In future we would also include the option of prerecorded movement paths. Many users (the economic and pastorally oriented in particular) would likely prefer constrained travel along the major road which traverses the valley. The ecologically inclined might want a route along the break of slope between the valley bottom and the break of hills while romantics may be happy to have movement constrained to scenic roads or hiking trails.

\section{Outcomes}

Two workshops were held in our Cudgewa Valley study area in late 2003. In these workshops various scenarios for the valley were discussed and evaluated with stakeholders. About 20 people attended on each occasion. Most were members of the local 'Landcare' group. They were given a brief introduction to the technology and to the plans for the evening. A representative of the regional catchment management authority led the workshops. In the first workshop management scenarios were explicitly identified with the four world-views (Table 3 ). These scenarios related to pasture type and pasture management level, riparian zone management and forest regeneration. Different management levels are the different degree of time, labour, energy applied to the land for pasture improvement, weed control, erosion control etc.

In the second workshop the focus was on possible land use without direct reference to the worldviews. Possible land uses included grazing (at three different management levels), softwood or hardwood plantations, vineyards, orchards, crops and vegetables. In addition, three different levels of riparian land management were available (as described in Table 4). No land use scenarios were defined in advance. Instead, participants brought forward notions of their own which we were later able to identify as corresponding to our world-view definitions. 
Consideration of futures in terms of world-views requires some recognition of the particular context. Land uses selected must be a realistic possibility. Among the five scenarios developed and evaluated by the workshop participants, four were later found to be easily interpreted as corresponding to the four world-views.

Economic: Where the workshop chose land uses to maximize economic return we identified the outcome as reflecting and economic world-view. However the constraint of public opinion was also relevant. Thus, although softwoods plantations might appeal to economic rationalists they meet widespread public opposition. More appealing were vegetables, hardwood plantations and orchards with gazing retained on the less productive lands.

Romantic: A scenario which included picturesque land uses such as orchards and vineyards, forest regeneration on the hills and retention of the visually attractive riparian willows was identified as romantic. A focus on recreation and scenery as the key landscape uses is maintained. The epitome of a romantic experience involves ex-urban migrants viewing the valley from houses newly built on the edges of fields and forests and/or a passive tourist sightseeing from air-conditioned cars.

Pastoral: The focus here was on traditional agricultural lifestyle - as lived by the parents and grandparents of the current farmers. Small scale agricultural activity is desired. Thus, grazing of annual pastures remained the dominant land use, with economic realities recognized in a high level of management.

Ecological: The workshop's most ecological scenarios chose land uses or management practices which maximized protection of the natural environment - particularly the qualities of the water, the soils and the habitat for native animals. Thus, forest regeneration, the use of perennial pastures and high management of the riparian zones were key elements.

Figure 3 shows the four options that exemplify (in our interpretation) the world views, while Table 4 describes these land use mixes. People were able to rate electronically these future options. The most popular was the ecological option (4.1 on a scale of 1 to 5 ), followed by the romantic (3.7), and pastoral (3.0) and well behind, the economic (2.5). The number of recorded votes ranged between 14 and 18. The fifth developed scenario was one which included heavy use of softwood plantations. This was dismissed by the audience without proceeding to a vote. It seems to have fitted with no-one's world-view.

\section{Conclusion}

This paper describes the design and initial testing of an Envisioning System intended to help communities explore and evaluate possible futures. Participants in the first workshops interacted with the Envisioning System and were able to construct and evaluate alternative futures. The structure and presentation of alternative futures seems critical. Constructing initial scenarios based on world-views seems a useful way to increase the likelihood that important stakeholders' concerns will be included in the initial stages of public discussion. This is particularly true when there are a large number of possible alternatives land use or management options for an even larger number of land units. In such circumstances clear expression of world-views might not 
emerge through piece-meal manipulation. However, when (as in the second workshop) there are a limited range of land uses available in a small number of configurations free manipulation did produce options consistent with the major world-views.

Although we ran two successful workshops using our EvS, the time available and the size of the audience did not make it appropriate to make specific tests of the different indicators or presentation modes. A complete understanding of the systems preferences of people with different world-views would require a more controlled experimental environment and a large group of people involved.

This analysis has nevertheless illustrated the way in which awareness and understanding of the major world-views adopted in our society can help with planning for, or evaluation of, major software systems. Analyses such as conducted here can be particularly useful for systems in which human values are explored, environmental outcomes predicted, and community preferences identified.

\section{Acknowledgments}

The development of the envisioning system is being funded by Land and Water Australia (project UME-65). Bruce Hull's time in Melbourne was supported by a University of Melbourne Visiting Fellow grant.

\section{References}

Allen, W., Kilvington, M., Horn, C. (2002) Using participatory and learning-based approaches for environmental management to help achieve constructive behaviour change. Landcare Research Contract Report LC0102/057, Lincoln, New Zealand. Available from: http://www.landcareresearch.co.nz/research/social/par_rep.asp (accessed 11/02)

Bergquist, G., and C. Bergquist. 1999. Post decision assessment. In V. H. Dale and M. R. English (eds). Tools to aid environmental decision making. Springer, Berlin, Germany.

Botkin, D. B. 1990. Discordant harmonies: a new ecology for the twenty-first century. Oxford University Press, New York.

Brail, R.K. and Klosterman, R.E. (2001) Planning Support Systems: integrating geographic information systems and visualization tools. ESRI Press, Redlands CA.

Chen, X., I. D. Bishop, and A. R. Abdul Hamid, (2002) Community exploration of changing landscape values: the role of the virtual environment, Proceedings of Digital Image Computing - Techniques and Applications, 273-278, Melbourne, January 2002.

Dunlap, T. R. (1999). Nature and the English Diaspora: Environment and History in the United States, Canada, Australia, and New Zealand. Cambridge, Cambridge.

Ervin, S. (1992). Intra-Medium and Inter-Media Constraints. In G. Schmitt (Ed.), CAAD Futures '91 (p. 365-380) Braunschweig: Vieweg.

Gundersen, A. G. (1995). The environmental promise of democratic deliberation. Madison, The University of Wisconsin Press. 
Klosterman, R.K. (2001) The What if? planning support system. In R. K. Brail and R. E. Klosterman (eds) Planning Support Systems: integrating geographic information systems and visualization tools.Redlands, CA, ESRI Press: 262-284.

Kwartler, M. and R. N. Bernard (2001). CommunityViz: an integrated planning support system. In R. K. Brail and R. E. Klosterman (eds) Planning Support Systems: integrating geographic information systems and visualization tools. Redlands, CA, ESRI Press: 285-308.

Michael, D.N. (1995) Barriers and bridges to learning in a turbulent human ecology. In: Gunderson, L.H; Holling, C.S.; Light, S.S. (eds.) Barriers and bridges to the renewal of ecosystems and institutions. New York, Columbia University Press. Pp. 461-485.

Pickett, S. T. A., R. S. Ostfeld, M. Shachak, and G. E. Lickens. (1997) The ecological basis of conservation: heterogeneity, ecosystems, and biodiversity. Chapman \& Hall, New York.

Robertson, D. and Hull, R.B. (2001a) Which Nature? A Case Study of Whitetop Mountain. Landscape Journal 20: 1-10.

Robertson, D. and Hull, R.B. (2001b) Beyond Biology: Toward a More Public Ecology for Conservation. Conservation Biology 14:325-340.

Stoakley, R., Conway, M. J., and Pausch, R. (1995) Virtual Reality on a WIM: Interactive Worlds in Miniature. In CHI 1995 - Conference on Human Factors in Computing Systems, pp 265-272, Denver, Co.

Stock, C and Bishop, I.D. (2002) Immersive, interactive exploration of changing landscapes. IEMSs 2002 - Integrated Assessment and Decision Support, Lugano, Switzerland, International Environmental Modelling and Software Society (iEMSs) 1: 30-35.

Takacs, D. (1996). The idea of biodiversity: philosophies of paradise. Baltimore, Johns Hopkins University Press.

United Nations (1992) Earth Summit Agenda 21: Rio Declaration on Environment and Development. (http://www.un.org/esa/sustdev/agenda21.htm. Accessed 11/02).

Verbree, E., van Maren, G., Germs, R., Jansen, F., and Kraak, M.-J. (1999). Interaction in virtual world views-linking 3D GIS with VR. International Journal of Geographical Information Science, 13, 385-396.

Walker, B., S. Carpenter, J. Anderies, N. Abel, G. Cumming, M. Janssen, L. Lebel, J. Norberg, G. D. Peterson, and R. Pritchard. (2002) Resilience management in social-ecological systems: a working hypothesis for a participatory approach. Conservation Ecology 6(1): 14. [online] URL: http://www.consecol.org/vol6/iss1/art14

Worster, D. (1994). Nature's economy: a history of ecological ideas. Cambridge, England, UK., Cambridge University Press.

Yankelovich, D. (1991). Coming to public judgment: making democracy work in a complex world. Syracuse, New York, USA, Syracuse University Press. 
Table 1 The options that exist for data representation within a futures envisioning system.

\begin{tabular}{|l|l|}
\hline Dimension & Options \\
\hline Form of expression & Verbal, Pictorial, Tabular \\
\hline Dimension & 2D, 2.5D, 3D \\
\hline Surface coding & Hatch, colour, iconic, generic texture, real texture \\
\hline Linkage & Stand-alone, internal hyperlinked, web capable \\
\hline Interactivity & No, Yes (-> further range of options) \\
\hline Temporal component & Static, Dynamic \\
\hline Physical Elements & $\begin{array}{l}\text { landform; vegetation; water; structures; animals (including } \\
\text { people); atmosphere; legal boundaries }\end{array}$ \\
\hline Objects & Specific versus Generic trees, houses etc \\
\hline Orientation & Vertical, oblique, horizontal \\
\hline Coordinate system & None, cartesian, projection \\
\hline Presentation & Paper, video, computer screen, immersive display \\
\hline Immersion & No, Head mounted display, wide screen \\
\hline Movement & Constrained, free; 2D or 3D \\
\hline Sound & No, Yes (Mono, stereo, positional) \\
\hline
\end{tabular}


Table 2. Some of the indicator options relevant to the Cudgewa valley, classified by world-view.

\begin{tabular}{|c|c|c|c|}
\hline Romantic & Pastoral & Ecological & Economic \\
\hline $\begin{array}{l}\text { Scenery } \\
\text { Hiking trail }(\mathrm{Km}) \\
\text { Remote campsites } \\
\text { Solitude } \\
\text { Remoteness } \\
\text { Naturalness } \\
\text { Visible development } \\
\text { Pollution } \\
\text { Km paved road } \\
\% \text { area not in } \\
\text { cultivation/urban } \\
\text { Age of forest }\end{array}$ & $\begin{array}{l}\text { Agricultural output } \\
\text { Agricultural support } \\
\text { services } \\
\text { Local Processing } \\
\text { capability } \\
\text { Small roads } \\
\text { Weed infestation } \\
\text { Soil erosion } \\
\text { Water quantity } \\
\text { Community festivals } \\
\text { Community services } \\
\text { Regional population } \\
\text { Tax rate } \\
\text { Local jobs } \\
\text { Pollution } \\
\text { Risk of Bushfire } \\
\text { Absence of } \\
\text { gentrification }\end{array}$ & $\begin{array}{l}\text { Biodiversity } \\
\text { Habitat types } \\
\text { Native species } \\
\text { Keystone species } \\
\text { Weed infestation } \\
\text { Endangered species } \\
\text { Fragmentation } \\
\text { Wildlife migration } \\
\text { corridors } \\
\text { Amount of biocides } \\
\text { Amount of fertilizer/ } \\
\text { nutrient load } \\
\text { River water quality } \\
\text { Soil erosion } \\
\text { Soil salinity } \\
\text { Pollution } \\
\text { Age of forest } \\
\text { Risk of bushfire }\end{array}$ & $\begin{array}{l}\text { Industry } \\
\text { Local jobs } \\
\text { Tourism attractions } \\
\text { Transportation } \\
\text { Infrastructure } \\
\text { Access to power, } \\
\text { water, sewer } \\
\text { Land value } \\
\text { Tax rate } \\
\text { Water quantity } \\
\text { Volume timber } \\
\text { Soil erosion } \\
\text { Soil salinity } \\
\text { Exports by sector } \\
\text { Community services } \\
\text { Unused capacity } \\
\text { Risk of bushfire } \\
\text { Local Processing } \\
\text { capability }\end{array}$ \\
\hline
\end{tabular}


Table 3. Land management configurations assessed by the first workshop. The attribution to specific world-views was made explicit.

\begin{tabular}{|l|l|l|l|}
\hline & $\begin{array}{l}\text { Flat and medium } \\
\text { slope land }\end{array}$ & Upper Slopes & Riparian \\
\hline Romantic & $\begin{array}{l}\text { Medium management } \\
\text { grazing (some weed } \\
\text { control, no soil } \\
\text { improvement) }\end{array}$ & $\begin{array}{l}\text { Forest regeneration } \\
\text { (stock removed, area } \\
\text { fenced) }\end{array}$ & $\begin{array}{l}\text { Low management } \\
\text { (willows species retained } \\
\text { and natural spread } \\
\text { permitted) }\end{array}$ \\
\hline Pastoral & $\begin{array}{l}\text { High management } \\
\text { level annual pastures } \\
\text { (high weed control, } \\
\text { soil improvement) }\end{array}$ & $\begin{array}{l}\text { low management } \\
\text { annual grazing (little } \\
\text { weed control) }\end{array}$ & $\begin{array}{l}\text { Medium management } \\
\text { (willows kept in check) }\end{array}$ \\
\hline Economic & $\begin{array}{l}\text { High management } \\
\text { level annual pastures } \\
\text { (high weed control, } \\
\text { soil improvement) }\end{array}$ & $\begin{array}{l}\text { low management } \\
\text { annual grazing (little } \\
\text { weed control) }\end{array}$ & $\begin{array}{l}\text { Low management } \\
\text { (willows species retained } \\
\text { and natural spread } \\
\text { permitted) }\end{array}$ \\
\hline Ecological & $\begin{array}{l}\text { Perennial pastures } \\
\text { (high management } \\
\text { levels required) }\end{array}$ & $\begin{array}{l}\text { Forest regeneration } \\
\text { (stock removed, area } \\
\text { fenced) }\end{array}$ & $\begin{array}{l}\text { High management } \\
\text { (willows removed, native } \\
\text { species replanted) }\end{array}$ \\
\hline
\end{tabular}

Table 4. Land use configurations assessed by the second workshop. The attribution to specific world-views was not explicit during the workshop.

\begin{tabular}{|l|l|l|l|l|}
\hline & Flat land & Medium slopes & Upper Slopes & Riparian \\
\hline Romantic & $\begin{array}{l}1 / 3 \text { vines } \\
2 / 3 \text { medium grazing }\end{array}$ & $\begin{array}{l}1 / 3 \text { orchards } \\
2 / 3 \text { medium grazing }\end{array}$ & $\begin{array}{l}2 / 3 \text { forest regeneration } \\
1 / 3 \text { medium grazing }\end{array}$ & $\begin{array}{l}\text { Low management } \\
\text { (willows retained and } \\
\text { extending) }\end{array}$ \\
\hline Pastoral & $\begin{array}{l}2 / 3 \text { crops } \\
1 / 3 \text { medium grazing }\end{array}$ & $3 / 3$ medium grazing & $\begin{array}{l}3 / 3 \text { low management } \\
\text { grazing }\end{array}$ & $\begin{array}{l}\text { Medium management } \\
\text { (willows kept in check) }\end{array}$ \\
\hline Economic & $\begin{array}{l}2 / 3 \text { vegetables } \\
1 / 3 \text { high management } \\
\text { grazing }\end{array}$ & $\begin{array}{l}1 / 3 \text { orchards, } 1 / 3 \\
\text { hardwoods, } 1 / 3 \text { high } \\
\text { management grazing }\end{array}$ & $\begin{array}{l}3 / 3 \text { high management } \\
\text { grazing }\end{array}$ & $\begin{array}{l}\text { Medium management } \\
\text { (willows kept in check) }\end{array}$ \\
\hline Ecological & $\begin{array}{l}3 / 3 \text { Perennial } \\
\text { pastures }\end{array}$ & $3 / 3$ Perennial pasture & $3 / 3$ Forest regeneration & $\begin{array}{l}\text { High management } \\
\text { (willows removed, native } \\
\text { species replanted) }\end{array}$ \\
\hline
\end{tabular}




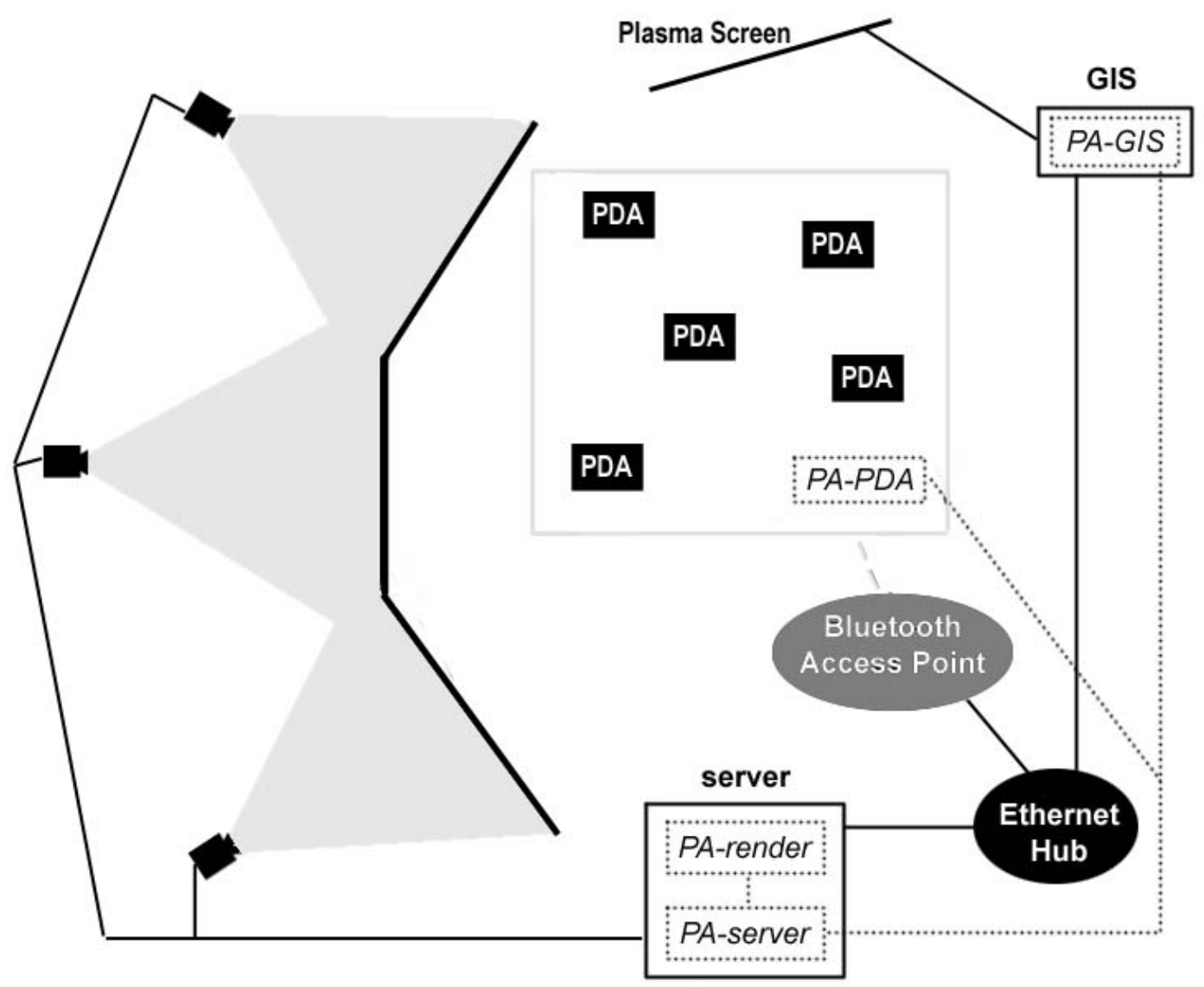

Figure 1. The set-up of our EvS. The screens are each $2.4 \mathrm{~m}$ wide and $1.8 \mathrm{~m}$ high. A $1.5 \mathrm{~m}$ plasma screen was used for the GIS display. 


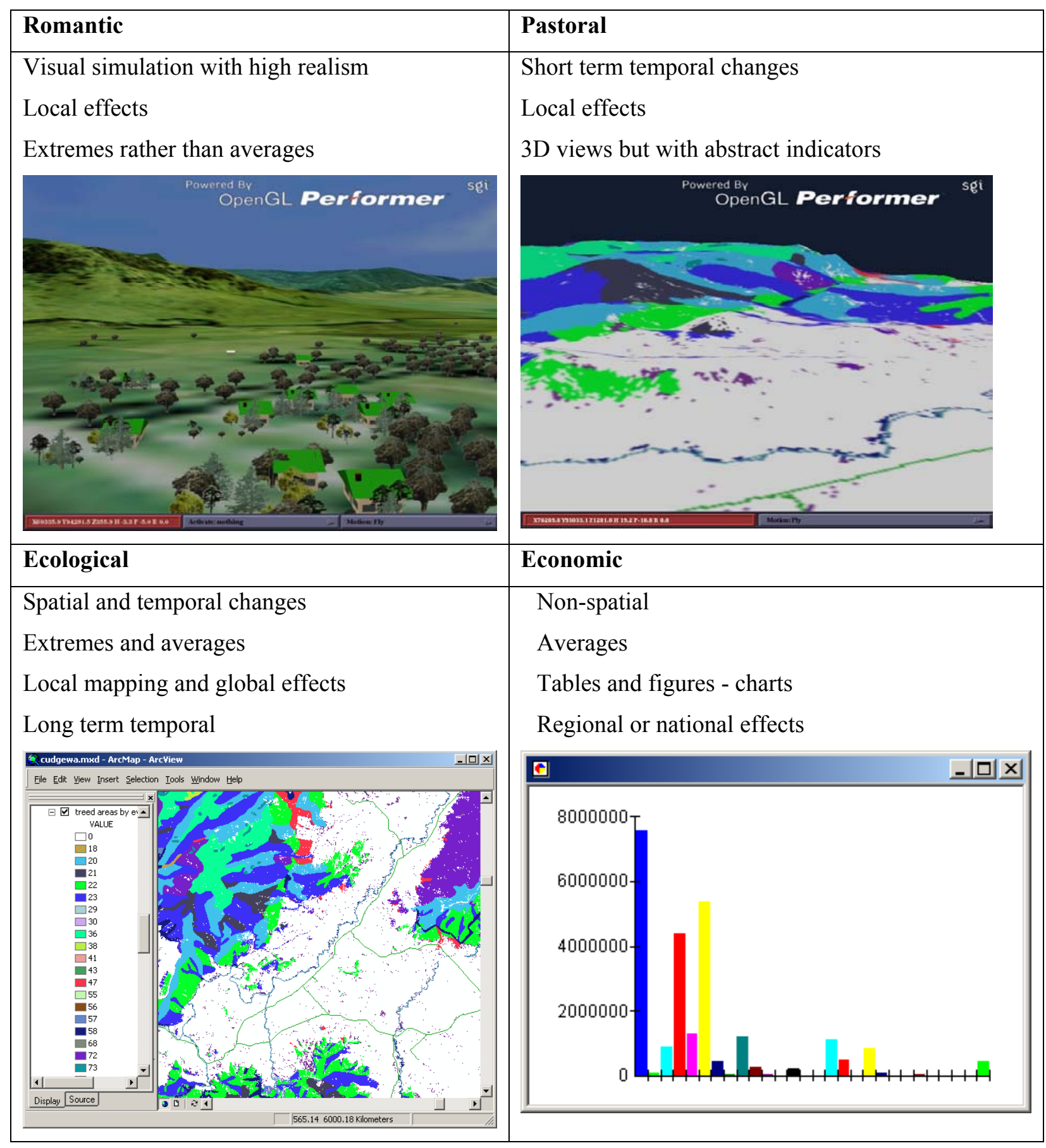

Figure 2. Some ideas, and example figures, on presentation preferences distinguished by worldview. 


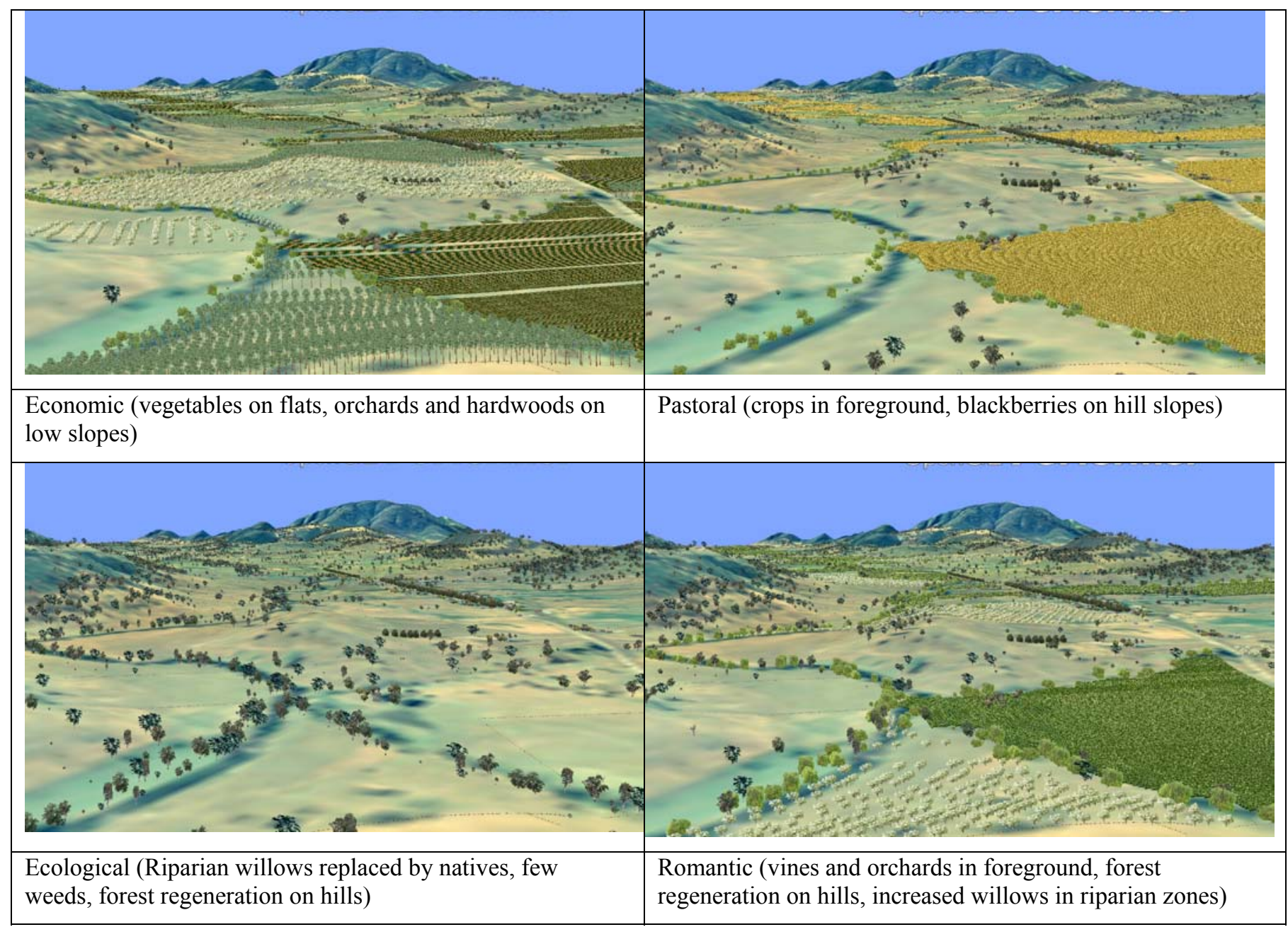

Figure 3. Examples from a common view-point of workshop outputs deemed to correspond to the four world views (colour versions are available at http://www.geom.unimelb.edu.au/cudgewa/simulations). 


\section{University Library}

\section{- M M I N E R VA A gateway to Melbourne's research publications}

Minerva Access is the Institutional Repository of The University of Melbourne

Author/s:

Bishop, ID;Hull, RB;Stock, C

Title:

Supporting personal world-views in an envisioning system

Date:

2005-12-01

Citation:

Bishop, I. D., Hull, R. B. \& Stock, C. (2005). Supporting personal world-views in an envisioning system. ENVIRONMENTAL MODELLING \& SOFTWARE, 20 (12), pp.1459-1468. https://doi.org/10.1016/j.envsoft.2004.06.014.

Publication Status:

Published

Persistent Link:

http://hdl.handle.net/11343/34163 